\title{
Round Isla
}

David Bullock and Steven North

When a scientific expedition visited Round Island in 1975 it found that introduced rabbits and goats had destroyed most of the vegetation, threatening the survival of the reptiles that depended upon it and causing soil erosion. (See Oryx, 14, page 51.) Eradication of the goats and rabbits was recommended. Seven years later the 1982 Round Island Expedition was launched to monitor the reptile, palm and alien mammal populations. ffPS contributed $£ 100$ which was raised through a special appeal. The authors, who participated in both surveys, report on the striking changes that have occurred in just seven years and discuss the future prospects for the island's wildlife, especially for the endemic reptiles.

Round Island, some $20 \mathrm{~km}$ off the north coast of Mauritius, has long been known as a place of exceptional biological interest. On its 151 ha of steep, rocky slopes are the last remnants of a palm savanna that once dominated the northern plain of Mauritius. Here too are relict populations of several reptile species that used to occur on the Mauritian mainland. The disappearance of both the palms and the reptiles on the mainland can be attributed to habitat destruction and predation by humans and their goats, pigs and rats. Indeed, there is some evidence that certain reptile species disappeared before people settled on Mauritius (Cheke, 1984). In this case, ship-borne rats may 36 well have been responsible for the extinctions. Regrettably, even uninhabited and inhospitable Round Island is not without alien mammals. Rabbits and goats, introduced in the early part of the nineteenth century, have irrevocably damaged the island. A hardwood forest has disappeared, the palm savanna has been reduced and there has been large-scale erosion. Fortunately, the Mauritius Government recognises the unique interest of Round Island and they are concerned to safeguard the endemic species that remain there.

We were members of scientific expeditions to Round Island in 1975 and 1982. The principal aim of both expeditions has been to monitor the reptile, palm and alien mammal populations. In this article, we describe the changes which have occurred between these years and what, if anything, can be done to prevent further deterioration of the palm savanna.

The work of our 1975 expedition was designed so that changes in the flora and fauna could be monitored. In that year, we divided the island into manageable units in which reptiles, palms and other plant species were counted in a standard manner. Similarly, belt transects for counting rabbits were marked out (Bullock, 1977). Much of this work was repeated in 1982. In addition, in 1978 an expedition from Edinburgh University counted reptiles in several of the same units and designated quadrats in which wedge-tailed shearwater Puffinus pacificus populations could be monitored. It is the results of these three expeditions that form the basis of our account. Our results are preliminary; a more detailed report will be published elsewhere in due course.

Oryx Vol 18 No 1 


\section{Vegetation changes since 1975}

There have been several significant changes between 1975 and 1982. The most striking affects the commonest tree, the lantan palm Latania loddigesii, which provides a variety of habitats vital to the endemic reptiles. This palm is now found only on Round Island and, in much smaller numbers, on a few other islets off Mauritius. It was once found throughout most of Round Island, including the steep exposed crater, but now fallen trunks and root bases are all that remain over large areas of eroded rock. In 1975 some 2500 mature lantan palms were counted, mostly on the relatively sheltered western slopes but also on the south and south-eastern slopes. By 1982 only 1580 remained. This represents a decline of 39 per cent but on parts of the southeastern slopes the decline has been as much as 84 per cent - and this over only seven years!

The direct reasons for the decline are fairly clear -erosion, senility and windblow. In many areas where shallow soils persist, burrowing by wedgetailed shearwaters also undermines the trees. However, the ultimate cause is the lack of replacement trees. Seedlings occur, and they are often numerous, wherever mature palms are found but the majority are grazed by rabbits at a very early age. On the south-eastern slopes virtually no seedlings survive to form young plants $(0 \cdot 1-1.25 \mathrm{~m}$ high) and, although the latter were more common on the western slopes, there has been a decline in this size class of 50-90 per cent since 1975.

Some encouraging signs were noted in 1982 such as the increase in thicket-sized (1.25-2 m high) lantan palms. Such thickets were virtually absent earlier this century, but were common on the Round Island in 1982

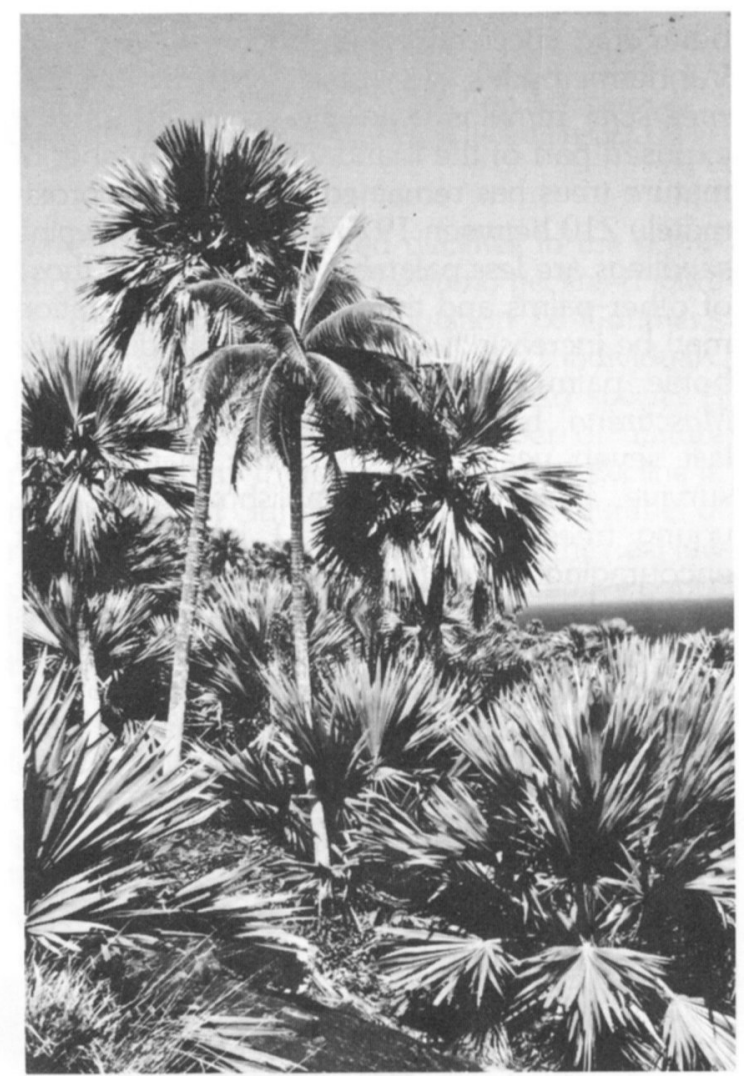

The sole surviving Round Island hurricane palm. This individual, surrounded by lantan palms, is situated on the western slopes.

western slopes in 1975. Since then the number has trebled and many are maturing to form trunks - a size class which has long been absent. Not only does this give some hope for a new generation of mature palms to replace the existing, depleted one but the increased thicket cover is an extremely valuable habitat for several of the 
endangered reptile species. There are, regrettably, no such encouraging signs on the southeastern slopes where the lantan palm is likely to become effectively extinct in the near future. It should also be remembered that erosion on the western slopes remains a threat to the palms throughout their life. Between 1975 and 1982 a large part of the formerly rich north-west of the island was subject to major sheet erosion and loss of vegetation.

Whilst the lantan palm is the most numerous palm and contributes most to the ecosystem, several other tree species were important in the past. Vandermeersch's screwpine Pandanus vandermeerschii remains especially important on the exposed part of the island where the number of mature trees has remained constant at approximately 210 between 1975 and 1982 . Screwpine seedlings are less palatable to rabbits than those of other palms and the amount of regeneration may be increasing. The endemic and distinctive bottle palm Hyophorbe amaricaulis, formerly Mascarena, has decreased in number over the last seven years and only nine mature trees survive. However, the establishment of seven young trees (all now over $1 \mathrm{~m}$ tall) is most encouraging since they probably represent the first bottle palms to become established this century. There is no such good news for the final palm species, the Round Island variety of the hurricane palm Dictyosperma album var conjugatum. Of the five mature trees which were present in 1975, only one still stands. No regeneration has been found and five young plants that were grown from Round Island seed and planted in 1978 have disappeared. This species will almost certainly become extinct on the island soon.

Other apparent changes in the vegetation include increases in the extent of tobacco Nicotiana tabaccum and of the creeper Tylophora laevigatum which is now choking other vegetation and young trees. Two indigenous woody plants have been rediscovered on Round Island since 1975 -the shrub Fernelia buxifolia and the leguminous tree Gagnabina pterocarpa. Only single individuals of each were found and the latter species now represents all that survives of the species rich hardwood forest which once occupied the upper slopes of the island. For this 38 reason it (and some of the young bottle palms) have been protected from rabbit grazing by temporary exclosures.

\section{Changes in the reptile populations since 1975}

There are eight species of reptile on Round Island (Table 1). In addition to the four species found nowhere else, Round Island is the stronghold for Bojer's skink and the Serpent Island gecko. Both species occur on other islands off the north coast of Mauritius (Bullock and Bloxam, 1984; Vinson and Vinson, 1969) but it is on Round Island that they are probably most abundant. Vinson's gecko and Bouton's skink are not endangered species; both occur on the Mauritian mainland and on several other islands. However, the former is primarily arboreal and as such is a useful indicator of the state of the palm savanna. Bouton's skink is confined to coastal rocks on Round Island, where it is uncommon; it will not be considered further in this report.

\section{Round Island boas}

Bolyeria multocarinata and Casarea dussumieri, the Round Island boa and the keel-scaled boa respectively, are endangered. Despite intensive searches, the Round Island boa was not found in 1982. The last sightings were of single, adult specimens in 1967 and 1975 (Bullock, 1977; Vinson, 1975). It is likely that the prime habitat for this snake was the ground layer beneath the hardwood forest. The latter was probably the first habitat to be destroyed by goats and rabbits and as a consequence the Round Island boa population probably declined at an earlier period than that of other species.

Table 1. The reptile species on Round Island. Asterisks indicate those species now found only on Round Island
Snakes

* Round Island boa

* Keel-scaled boa

Lizards

* Gunther's gecko

Vinson's gecko

Serpent Island gecko

* Telfair's skink

Bojer's Skink

Bouton's skink
Bolyeria multocarinata

Casarea dussumieri

Phelsuma guentheri

Phelsuma omata (vinsoni)

Cyrtodactylus serpensinsula

Leiolopisma telfairii

Scelotes (Gongylomorphus) bojerii

Cryptoblepharus (Ablepharus)

boutonii
Oryx Vol 18 No 1 


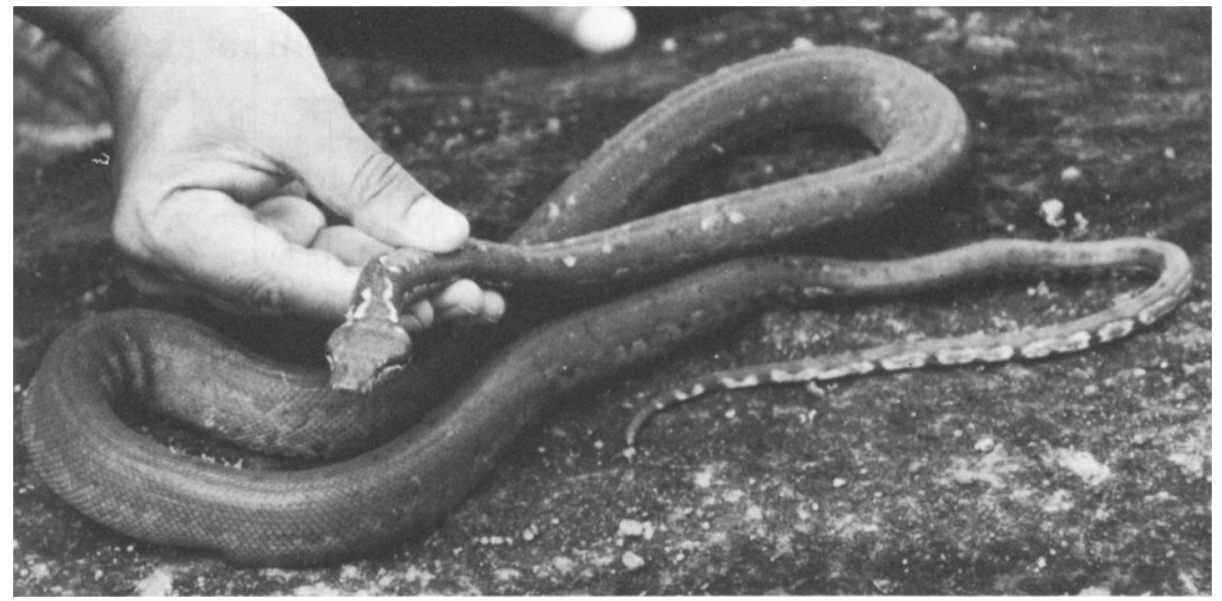

A large

female keel-scaled boa on Round Island

The population of the keel-scaled boa appears to be low but stable or increasing. In approximately 150 person-hours of searching in the palm savanna, we found 26 in 1975 and 58 in 1982. The apparent increase in the population is possibly a result of increased success in finding snakes in the latter year. Recruitment appears to have been similar in the two years: In 197515 per cent of the snakes had the orange-brown colour of immatures; the corresponding figure for 1982 was 14 per cent. Of 49 that could be sexed, 21 were male and 28 female. Three males were collected to augment the captive breeding colony at the Jersey Wildlife Preservation Trust.

\section{Geckos}

Concomitant with a decline in the number of mature lantan palms between 1975 and 1982, there have been marked declines in the populations of the arboreal Phelsuma geckos (Figure 1). In particular, the population of Gunther's gecko may be as low as $100-150$ individuals. The abundance of both these gecko species is closely correlated with the number of mature palms. We may therefore see a further decline in the number of Gunther's geckos if the number of mature palms continues to decline in the next few years as expected. Fortunately, the captive population in the Jersey Wildlife Preservation Trust is thriving and expanding.

The small, nocturnal, Serpent Island gecko is difficult to census. However, our preliminary results suggest that the population size has not changed markedly since 1975 when there were estimated to be between 3000 and 4000. During night searches in 1975, the number seen per person-

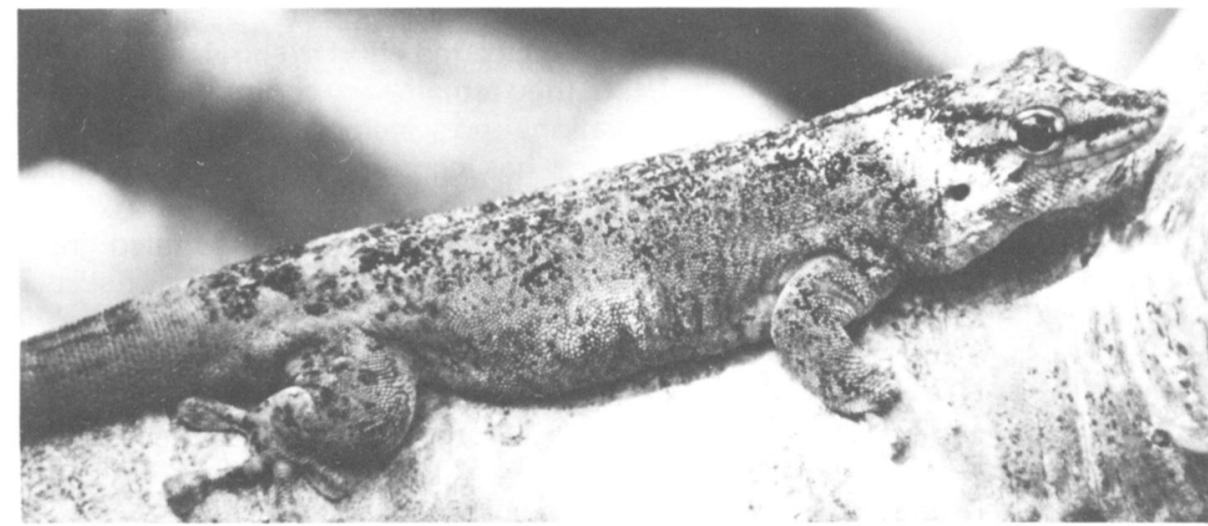

Gunther's gecko on a screwpine branch on Round Island 

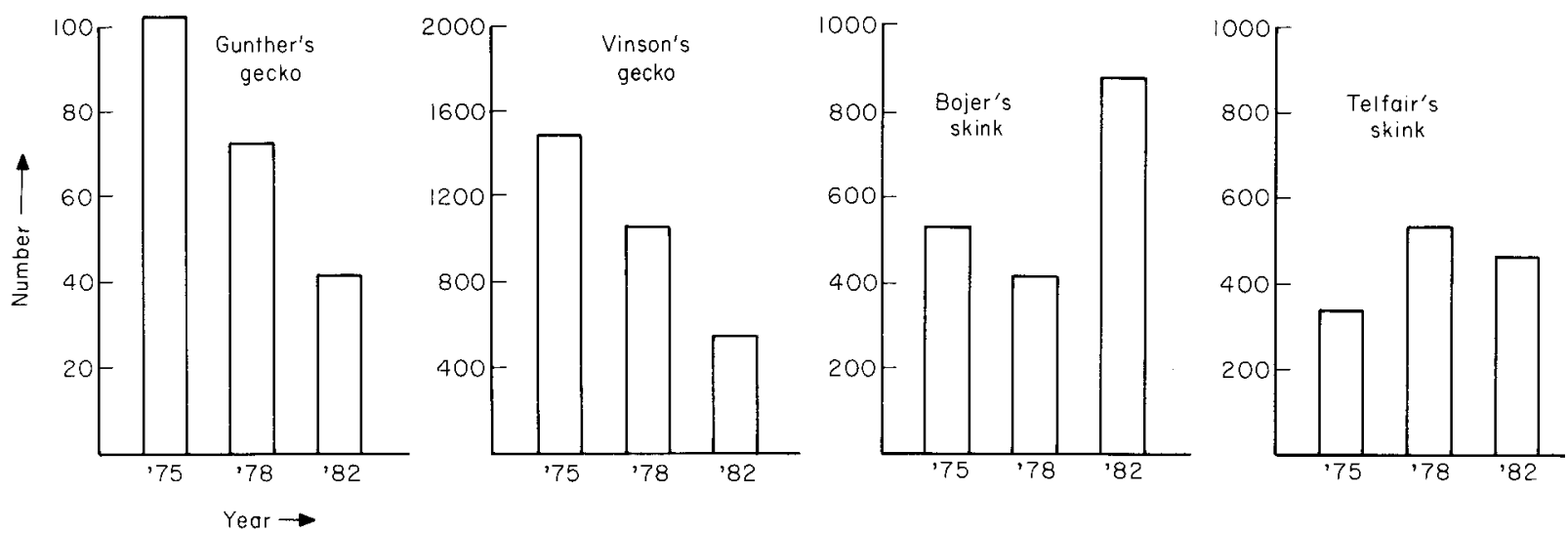

Figure 1. Population changes of Round Island lizards between 1975 and 1982 . The histograms show indices of abundance obtaine by standardised counting of 30 ha of the palm savanna.

hour was roughly $1 \cdot 7$; the corresponding figure for 1982 was 1.8 , suggesting little change. Another population of this species was discovered on nearby Gunner's Quoin during our survey of this island (Bullock and Bloxam, 1984); Serpent Island geckos had previously been found only on Serpent Island and Round Island. The Serpent Island gecko may still exist on the Mauritian mainland where it is believed to have been extinct for several centuries (Cheke, 1984).

\section{Skinks}

The large, bold Telfair's skink was at least as numerous in 1982 as in 1975 when the population estimate was $4000-5000$ (Figure 1). The population is unlikely to decline in step with a deterioration in the palm savanna as the species does not depend on trees as a habitat. Telfair's skink does, however, need cover of some sort and will probably decline as certain areas of the island become denuded of tree cover.

Bojer's skink is abundant on Round Island and remains by far the commonest reptile. As with Telfair's skink, the population may well decline in response to the decline in tree cover. The apparent large increase in population size as judged by sample counts (Figure 1), may in part be the result of differences in skink activity (and therefore visibility) on different counting days due to varying weather conditions.

\section{Rabbits and goats}

Perhaps the most significant event in Round Island's recent history has been the extermination of feral goats, first introduced in 1844. In 1976 marksmen shot all but two individuals and although dung was found in 1982, it was very old and no goats were seen. The recent decline and removal of the goats may well have resulted in the observed increase in thickets and newly mature lantan palms as well as the establishment of some young bottle palms and increased screwpine regeneration. It may also have led to the increase of the creeper Tylophora, which was grazed by goats, and this plant could present a serious problem in the future.

Despite a concerted effort to shoot out the rabbits in 1976, they remain very common. Indeed, field observations and systematic counts show that the population has increased from between 650 and 1500 in 1975 to between 2450 and 2900 in 1982. This increase and the associated grazing has markedly reduced the amount of seedling lantan palms and continues to limit severely or prevent the regeneration of the palm savanna over large areas. Heavy grazing has allowed the spread of certain plants (e.g. tobacco) and, by maintaining an open ground cover, also renders many areas susceptible to erosion.

Oryx Vol 18 No 1 


\section{Prospects for the future}

Despite the large population of rabbits, the palm savanna is showing signs of regeneration. However, because of the dependency of the arboreal geckos on mature palms and because the palms are very slow growing, there will be periods in the next few decades when prime gecko habitat is scarce. The resultant habitat loss may well cause the extinction of Gunther's gecko in the wild. Similarly, any further large-scale erosion will reduce the habitats and the available prey for snakes and Telfair's skink.

From our preliminary surveys of several Mauritian islets and our more detailed survey of Gunner's Quoin, it is clear that rats (either the ship rat Rattus rattus or the brown rat $R$. norvegicus) have had a destructive effect on the reptile fauna. Neither Round Island nor Serpent Island have rat populations and it is vital that they are never introduced. Fortunately neither island is regularly visited but large parties of fishermen continue to harvest sea-birds illegally (mainly red-tailed tropic birds Phaeton rubricauda) and through their landings could accidentally introduce rats or mice.

Attempts at eradication of rabbits have so far been unsuccessful. We cannot overstate the futility of one-off 'shoot outs' on Round Island as a method of removing the rabbit population; depending on the time of year, a partial removal of rabbits may increase the food and shelter for the remaining individuals giving rise to larger litters and resulting in a temporary but very damaging population explosion. Now that goats have been removed, there appears to have been a large increase in creeper cover (especially of Tylophora). This species was found to be smothering young palms and the remaining hardwood tree in 1982. The spread of creeper should be monitored and efforts made to clear it from trees.

In addition to the destructive effects of introduced mammals, we believe that the impact of wedgetailed shearwaters on the Round Island environment has been great and, until recently, underestimated. In some areas where pockets of soil survive, shearwaters are probably the main factor limiting recovery of the vegetation. ComRound Island in 1982 parison of quadrats in several parts of the colony during 1978 and 1982 has revealed a large increase in population size. In 1978 the population was estimated to be between 15,000 and 20,000 pairs. Our 1982 estimate, derived from similar census methods, was much higher at between 50,000 and 100,000 pairs (Bullock et al., 1982). Regular monitoring of the shearwater population is recommended.

Using the census methods established in 1975, it will be possible to monitor the flora and fauna of Round Island in future years. This will be particularly important in the event of a major environmental change such as a cyclone or eradication of the rabbits.

\section{Acknowledgments}

We thank the sponsors of the Round Island 1982 Expedition of which this study formed a part. In particular, we thank the Fauna and Flora Preservation Society for organising a fundraising appeal on our behalf, through the Oryx 100\% Fund. Conservation work in Mauritius would not be possible without the dynamism and co-operation of Wahab Owadally: to him, and his staff in the Forest Service, we offer sincere thanks. The other members of the 1982 expedition, namely: $Q$. Bloxam, S. Greig, Y. Mungroo, B. Osborne and D. Snelson, ably conducted the field-work with us and provided excellent companionship. J.B. Alexander, C. Duck and A. Gardner kindly allowed us to use unpublished data from the Edinburgh University expedition to Round Island in 1978.

\section{References}

Bullock, D. 1977. Round Island: a tale of destruction. Oryx, 14(1), 51-58.

Bullock, D. and Bloxam, Q. 1984. An undescribed subspecies of Cyrtodactylus serpensinsula (Loveridge): Reptilia: Sauria; Gekkonidae; C. s. coindemirensis ssp nov.. from Gunner's Quoin, Mauritius. Bull. Maurit. Inst. In press.

Bullock. D., Greig. S., North, S., Osborne, B. and Snelson, D. 1982. Round Island Expedition 1982: Preliminary Report. Unpublished.

Cheke, A.S. 1984. A review of the ecological history of the Mascarene Islands, with particular reference to extinctions and introductions of land vertebrates. In Studies of the Mascarene Avifauna. (Ed. A.W. Diamond). Cambridge University Press. In press.

Vinson, J. and Vinson, J.-M. 1969. The saurian fauna of the Mascarene Islands. Bull. Maurit. Inst. 6(4), 203-320.

Vinson, J. 1975. Notes on the reptiles of Round Island. Bull. Maurit. Inst. 8(1), 49-67.

David Bullock, Department of Botany. The University. St Andrews, Fife KY16 9AL, UK.

Steven North. Highfield. Stephen Avenue, Dufftown. AB5 4BH, UK 